\title{
ANATI QUANTI: SOFTWARE DE ANÁLISES QUANTITATIVAS PARA Estudos em ANATOMia Vegetal ${ }^{1}$
}

\author{
ANATI QUANTI: Quantitative Analysis Software for Plant Anatomy Studies
}

AGUIAR, T.V. ${ }^{2}$, SANT'ANNA-SANTOS, B.F. ${ }^{3}$, AZEVEDO, A.A. ${ }^{4}$ e FERREIRA, R.S. ${ }^{5}$

\begin{abstract}
RESUMO - Em diversos estudos interdisciplinares em que a Anatomia Vegetal é utilizada, análises quantitativas complementares são necessárias. Geralmente, a avaliação micromorfométrica é feita manualmente e/ou utilizando programas computacionais de análise de imagens não específicos. Este trabalho teve como objetivo desenvolver um programa específico para Anatomia Vegetal quantitativa e testar sua eficiência e aceitação por usuários. A solução foi elaborada na linguagem Java, visando maior mobilidade em relação ao sistema operacional a ser usado. O software desenvolvido foi denominado ANATI QUANTI e testado pelos alunos, pesquisadores e professores do Laboratório de Anatomia Vegetal da Universidade Federal de Viçosa (UFV). Todos os entrevistados receberam fotos para efetuarem medições no ANATI QUANTI e comparar com os resultados obtidos utilizando o software disponivel. Os voluntários, através de questionários previamente formulados, destacaram as principais vantagens e desvantagens do programa desenvolvido em relação ao software disponível. Além de ser mais específico, simples e ágil do que o software disponível, o ANATI QUANTI é confiável, atendendo à expectativa dos entrevistados. Entretanto, há necessidade de acrescentar recursos adicionais, como a inserção de novas escalas, o que aumentaria a gama de usuários. O ANATI QUANTI já está em uso nas pesquisas desenvolvidas por usuários na UFV. Por ser um software livre e de código aberto, será disponibilizado na internet gratuitamente.
\end{abstract}

Palavras-chave: análise micromorfométrica, Java, densidade estomática, índice estomático.

\begin{abstract}
Complementary quantitative analyses are necessary for several interdisciplinary studies using Plant Anatomy. Generally, micromorphometric evaluation is performed manually and/ or using non-specific software for image analyses. This work aimed to develop specific quantitative analysis software for Plant Anatomy and test its efficiency and acceptance by users. The solution was elaborated in the JAVA language, which has a greater mobility in relation to the operating system to be used. The software developed was called ANATI BUANTI and tested by students, researchers and professors of the Plant Anatomy Laboratory of the Universidade Federal de Viçosa (UFV). All the interviewees received photos to measure in ANATI QUANTI and compare with the results obtained using the available software. Through previously formulated questionnaires, the volunteers pointed out the main advantages and disadvantages of the developed software in relation to the currently available software. Besides being more specific, simpler and faster than the currently available software, ANATI QUANTI is reliable, matching the interviewees expectations. However, additional resources need to be added as well as new scales to increase users range. ANATI QUANTI is already being applied in research developed by UFV users. It is a free software and as an open source, it it will be available for free over the internet.
\end{abstract}

Keywords: micromorphometric analysis, Java, stomatal density, stomatal index.

1 Recebido para publicação em 21.3.2007 e na forma revisada em 25.10.2007.

2 Graduando em Ciências da Computação pela Universidade Federal de Viçosa - UFV, Bolsista PIBIC/CNPq pelo Departamento de Biologia Vegetal - DBV, 36570-000 Viçosa-MG. ${ }^{3}$ Doutorando em Botânica pela UFV, Bolsista CAPES, <brunoufv@yahoo.com.br>. ${ }^{4}$ Professor Associado I do DBV/UFV; ${ }^{5}$ Professor Adjunto do Departamento de Informática - DPI/ UFV. 


\section{INTRODUÇÃO}

O estudo comparativo de células, tecidos e órgãos vegetais, denominado de Anatomia Vegetal, é uma disciplina da Botânica com longa tradição. Os anatomistas aplicam observações críticas e extensivas, resultando na compilação, codificação e análise de dados descritivos, utilizando métodos das ciências experimentais (Dickison, 2000).

Além da avaliação qualitativa, há também o emprego da análise quantitativa (micromorfométrica) em diversos estudos interdisciplinares em que a anatomia é utilizada. Em investigações anatômicas, vários são os exemplos de utilização de parâmetros quantitativos para confirmar a interpretação dos resultados: o comprimento e diâmetro de tricomas secretores foram utilizados para diferenciar nectários florais e extraflorais em Trumfetta semitriloba (Leitão et al., 2005); as características de digestibilidade de espécies forrageiras podem ser mais bem compreendidas quando complementadas com estudos de anatomia quantitativa em Brachiaria brizantha e B. humidicola (Alves de Brito et al., 2004); a contagem de estômatos e os cálculos de densidade e índice estomático são bastante utilizados na descrição anatômica de espécies, como em Chamaecrista trichopoda (Francino et al., 2006), e na análise da influência da intensidade luminosa na estrutura anatômica, como em Tradescantia pallida (Paiva et al., 2003), entre outras.

As análises micromorfométricas também contribuem para a caracterização das alterações na estrutura dos órgãos vegetais de plantas provocadas por agentes externos. Características da superfície foliar de espécies de eucalipto, como o número de células epidérmicas, podem ser relacionadas com a tolerância ao glyphosate (Tuffi Santos et al., 2005). Alguns caracteres anatômicos observados no cultivar RB855113 de cana-de-açúcar, como a maior densidade de estômatos e a maior proporção de células buliformes, podem explicar a maior penetração do trifloxysulfuron-sodium + ametryn e, conseqüentemente, a maior sensibilidade do cultivar a essa mistura de herbicidas (Ferreira et al., 2007).

Burrows et al. (1992) documentaram as alterações provocadas pelo paclobutrazol na estrutura foliar de Chrysanthemum por meio das dimensões de várias estruturas anatômicas. Análises quantitativas, detalhando a proporção entre os diferentes tecidos da folha e a quantidade de estruturas na epiderme, auxiliam na identificação de diferenças na sensibilidade de espécies aos efeitos negativos da poluição atmosférica (Soukupova et al., 2001; Maranho et al., 2006) e de herbicidas (Ferreira et al., 2003; Tuffi Santos et al., 2004, 2005, 2006).

A análise quantitativa de fotomicrografias requer a avaliação detalhada de grande quantidade de material foliar (Feder \& O'Brien, 1968), o que torna a utilização de softwares de análise de imagens importante. Os primeiros computadores foram utilizados para efetuar cálculos matemáticos, possibilitando a obtenção de resultados rápidos e confiáveis de dados numéricos. Posteriormente, com a redução dos custos de memória (disco e memória principal), as aplicações de banco de dados e processamento de texto se popularizaram. O computador vem servindo de ferramenta de apoio para cálculo e organização da informação em diversas áreas das ciências biológicas (Veropoulos et al., 1998). O estudo de imagens, que é uma área da ciência da computação bem consolidada, pode ser usado para contagens, medidas de área, detecção de formas, entre outras (Falcão, 2006).

A Universidade Federal de Viçosa (UFV) destaca-se pela elevada demanda para aplicações da informática na biologia, principalmente no que se refere ao processamento e à análise de imagens. A análise quantitativa de caracteres anatômicos tem se constituído em uma ferramenta útil na interpretação de pesquisas desenvolvidas com herbicidas (Tuffi Santos et al., 2004, 2005, 2006; Ferreira et al., 2003, 2007), poluentes atmosféricos (Sant' Anna-Santos et al., 2007), dejetos de suinocultura (Barros, 2005) e caracterização anatômica (Leitão et al., 2005; Francino et al., 2006).

Softwares proprietários, aqueles cuja cópia, redistribuição ou modificação são em alguma medida proibidos pelo seu criador ou distribuidor (Wikipédia, 2007), em geral apresentam alto custo, o que restringe sua utilização, limitando a quantidade de computadores com esse recurso. Outra desvantagem é que softwares para processamento de imagens de uso geral, 
apesar de terem os recursos para resolver determinado problema, demandam grande período de tempo para o aprendizado, por incluir diversos tipos de ferramentas muitas vezes não utilizadas pelo usuário. Além disso, podem ocorrer limitações na exportação dos resultados para outros softwares, gerando dificuldades de compatibilização com outros programas.

Em contrapartida, softwares livres, além de não terem restrições de uso, podem ser adaptados e modificados para resolver determinados problemas, simplificando a interface com o usuário, automatizando tarefas específicas e sendo personalizado para exportar os dados da forma desejada, reduzindo desse modo o tempo de aprendizado e de uso.

Diante do exposto, objetivou-se desenvolver um software específico para análise quantitativa em Anatomia Vegetal e testar sua eficiência e aceitação pelos usuários.

\section{MATERIAL E MÉTODOS}

Para programação do software de medições em Anatomia Vegetal, utilizou-se a linguagem de programação Java. Para elaboração do programa, foram estudados assuntos como propriedades dos pixels, formatos de imagens, realce de imagens e identificação de bordas. Os algoritmos foram baseados em diferenciação de cor.

O formato das imagens a serem trabalhadas é o JPEG, uma compressão do BMP, já que as imagens ficam menos carregadas e não perdem informações relevantes às análises a serem realizadas.

\section{Detecção de imagens}

O primeiro passo na análise de imagens é a separação ou a segmentação dos objetos dentro da imagem. Algoritmos de segmentação permitem achar diferenças entre dois ou mais objetos. A separação é baseada em dois conceitos: similaridade e descontinuidade (Albuquerque, 2005).

Na segmentação, procura-se distinguir as partículas umas das outras e do fundo. Essa distinção permitirá ao programa interpretar pixels contíguos e agrupá-los em regiões. Não existe um modelo formal para a segmentação - o processo é essencialmente empírico; logo, esta etapa é a mais difícil do processo e também a mais delicada, pois todas as medidas serão realizadas sobre as regiões identificadas nesta etapa (Seara, 2007).

Para detecção de borda, foi utilizado o algoritmo do operador de Sobel (Gonzalez \& Woods, 2002), definido a seguir, para encontrar o gradiente da borda, que nada mais é que a razão segundo a qual sua coloração varia, baseado no método da vizinhança. Foi utilizada a 4-vizinhança, explicada em seguida, com o objetivo de exigir menos do computador do usuário, uma vez que é interessante que o programa funcione em qualquer computador.

\section{Detecção de borda}

A borda, ou contorno, é uma mudança brusca do nível de coloração entre duas regiões relativamente homogêneas. Ela pode aparecer como uma seqüência de pontos, uma linha, um segmento ou uma curva. Sua detecção é importante para que haja diferenciação entre duas regiões numa imagem, para posterior análise (Facon, 2005).

\section{Vizinhança de um pixel}

Há duas maneiras possíveis de se definir a vizinha de um pixel: 4-vizinhança e 8-vizinhança. A 4-vizinhança ou vizinhança simples de um pixel qualquer é definida como o conjunto dos pixels que ficam ao redor deste ponto, desconsiderando os pontos localizados nas diagonais. A 8-vizinhança de um dado pixel é definida como o conjunto de todos os pixels que ficam ao redor deste, incluindo, assim, as diagonais que passam por ele (Facon, 2005).

\section{Operador de Sobel}

O operador de Sobel é um detector de bordas utilizado para obter descontinuidades na coloração da imagem, ou seja, ele permite a determinação de seus contornos. Esse operador utiliza duas matrizes, ou máscaras, com valores que representam a possível variação da coloração para detectar se o ponto faz parte ou não de algum contorno. Essas máscaras são 
definidas como gradiente vertical e horizontal (Filho, 2007).

\section{Teste do software e pesquisa de opinião com usuários}

Para avaliar a eficiência do software desenvolvido, foram realizadas medições de área em 50 imagens de cortes transversais da folha de Spondias dulcis cedidas pelo Laboratório de Anatomia Vegetal (UFV), no software proprietário e no ANATI QUANTI.

Para testar a aceitação do ANATI QUANTI pelos usuários que utilizam o software proprietário com freqüência, foi realizada uma palestra de exposição do programa no DBV/UFV. Após a palestra, onde os usuários receberam informações acerca da utilização do ANATI QUANTI, foram distribuídos questionários de opinião sobre o programa a 12 voluntários. No questionário, todos os entrevistados forneceram nome completo, condição dentro da UFV (docente, pós-graduando ou graduando), departamento e e-mail para contato. Os seguintes questionamentos foram feitos aos entrevistados acerca do ANATI QUANTI:

a) Em sua opinião, quais as principais vantagens do software ANATI QUANTI sobre o software disponivel? Enumere, de 1 a 9, em ordem crescente de importância.

( ) As escalas já estão inseridas, não sendo necessário calibrar o software.

( ) A abertura das imagens é fácil, basta selecionar a pasta que as imagens vão abrindo em ordem seqüencial.

( ) Caso seja desejável, as imagens já abrem com contraste invertido, o que reduz o tempo de trabalho na edição das imagens em outros softwares.

( ) A exportação dos dados é direta; nas planilhas geradas, todas as medições já aparecem com o nome da figura ao lado, não sendo necessário perder tempo formatando as planilhas do Excel $^{\circledR}$.

( ) A contagem de células é prática, havendo opções de botões diferenciados para estômatos e células epidérmicas propriamente ditas. Dessa forma, os dados já são exportados diretamente para o Excel $^{\circledR}$, não havendo necessidade de calcular densidade e índice estomático; os valores já são inseridos automaticamente, tornando o trabalho mais rápido $\mathrm{e}$ prático.

( ) O software é gratuito, o que evita a pirataria de softwares pagos e facilita o acesso.

( ) O software roda nas plataformas Linux e Windows ${ }^{\circledR}$.

( ) O fato de o software ser em português auxilia na compreensão das suas funções.

( ) O software é simples e específico para o que quero utilizar, com poucos botões e funções, o que facilita a memorização e utilização dos recursos disponiveis.

b) Dos itens listados abaixo, quais você julga mais importantes a serem acrescentados numa segunda versão do ANATI QUANTI? Enumere, de 1 a 4 , em ordem crescente de importância.

( ) Inserção de novas escalas. As escalas inseridas são específicas para o microscópio Olympus AX70TRF, havendo necessidade de calibrar o software para imagens provenientes de outros microscópios.

( ) Falta a ferramenta sobre medições de área e espessura manuais.

( ) Demo de utilização. Não consigo utilizar o software sozinho (a); seria ideal haver um slide show em que haja uma demonstração de como utilizar.

( ) Disponibilização na internet, no site da UFV, para que as versões mais atuais estejam sempre disponiveis e fáceis de acessar.

c) Pretende utilizar o software ANATI QUANTI em suas pesquisas?

\section{( ) Sim ( ) Não}

Após o preenchimento do questionário, todos os voluntários assinaram um "Termo de consentimento livre e esclarecido", em que declararam que entenderam os objetivos da pesquisa. A porcentagem de relevância das vantagens e desvantagens do ANATI QUANTI sobre o software disponivel foi calculada de acordo com a média aritmética da pontuação dada pelos voluntários a cada um dos itens propostos no questionário. O resultado da média aritmética foi dividido pela maior ordem de importância dos itens. 
Adicionalmente, durante as atividades práticas da disciplina Métodos em Anatomia Vegetal do Programa de Pós-Graduação em Botânica, nove alunos receberam quatro imagens para serem mensuradas nos dois softwares e gentilmente forneceram comentários e sugestões orais, utilizados na discussão dos resultados.

\section{RESULTADOS E DISCUSSÃO}

\section{Características do software}

O software desenvolvido foi denominado ANATI QUANTI $($ ANATI $=$ anatomia vegetal $\mathrm{e}$ QUANTI = análise quantitativa). No menu lateral da esquerda observam-se as principais ferramentas nos botões: Abrir Imagem, Próxima Imagem, o modo com que elas serão apresentadas (com ou sem o contraste invertido), Inverter Imagem, Contagem Manual, Área e Espessura, Adicionar Dados e Gerar Planilha. No menu lateral da direita situam-se as funcionalidades relacionadas à contagem manual e a tabela de histórico das imagens que foram mensuradas. Na parte inferior da tela, o nome da imagem em análise (redimensionada na proporção original) e a escala em uso aparecem na barra de status (Figura 1A). Após comparar os dois softwares, os usuários destacaram que o ANATI QUANTI é fácil de utilizar, já que os recursos disponíveis estão localizados em poucos comandos, que são específicos para micromorfometria.

O botão "Próxima Imagem" carrega para a tela principal a próxima imagem da pasta selecionada a ser mensurada (Figura 1A). Uma vez que as análises são realizadas utilizandose muitas imagens, esta ferramenta é de grande utilidade, pois garante ao usuário a certeza de sempre estar abrindo, na seqüência correta, uma imagem ainda não mensurada. Segundo os alunos da disciplina Métodos em Anatomia Vegetal, esta ferramenta é muito útil, já que a garantia de estar medindo a imagem

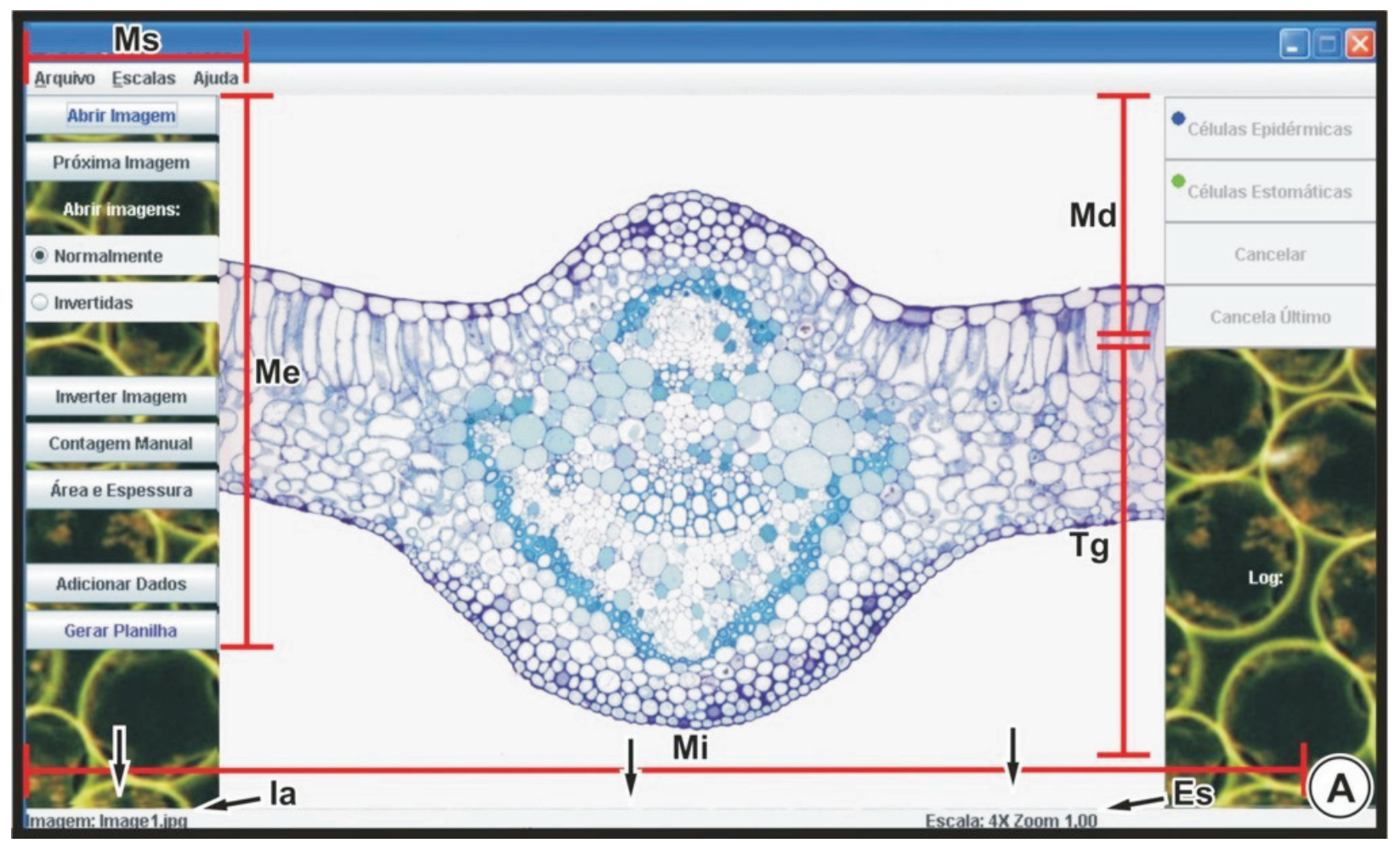

A. menu superior (Ms): seleção da escala a ser trabalhada; menu lateral esquerdo (Me): principais botões de comando; menu lateral direito (Md): funções da contagem manual e local destinado à tabela de log (Tg); menu inferior (Mi): nome da imagem em análise (Ia), escala utilizada na análise (Es).

Figura 1 - Interface geral do ANATI QUANTI. 
correta facilita o trabalho e diminui a probabilidade de erro durante a análise micromorfométrica.

Ao abrir as imagens, o usuário ainda tem a opção de escolher de que modo elas serão apresentadas: com (Figura 2A) ou sem o contraste invertido (Figura 2B). O comando "Inverter Imagem" inverte as cores da imagem corrente, o que pode contribuir para um destaque mais aparente dos diferentes tipos celulares em análise. No software proprietário, a maioria dos usuários executa o comando de inversão de contraste toda vez que uma imagem é aberta. Já no ANATI QUANTI, a opção de o usuário abrir as imagens com o contraste já invertido torna o trabalho mais prático e rápido.
O menu superior possui, como função principal, a seleção da escala a ser usada durante a análise da imagem. As escalas que são utilizadas nas análises de imagens provenientes do microscópio Olympus AX70TRF já estão inseridas no ANATI QUANTI (Figura 2C), tornando o software muito prático. No software proprietário, cada vez que o programa é reinstalado, há necessidade de inserir novamente as escalas. Os usuários que compararam os dois softwares observaram que a inserção automática de escalas do ANATI QUANTI padroniza as medições, caso haja necessidade de reinstalar o software novamente ou efetuar medições em computadores diferentes. Contudo, a inserção de novas escalas é um recurso desejável para usuários de outros microscópios, constituindo-

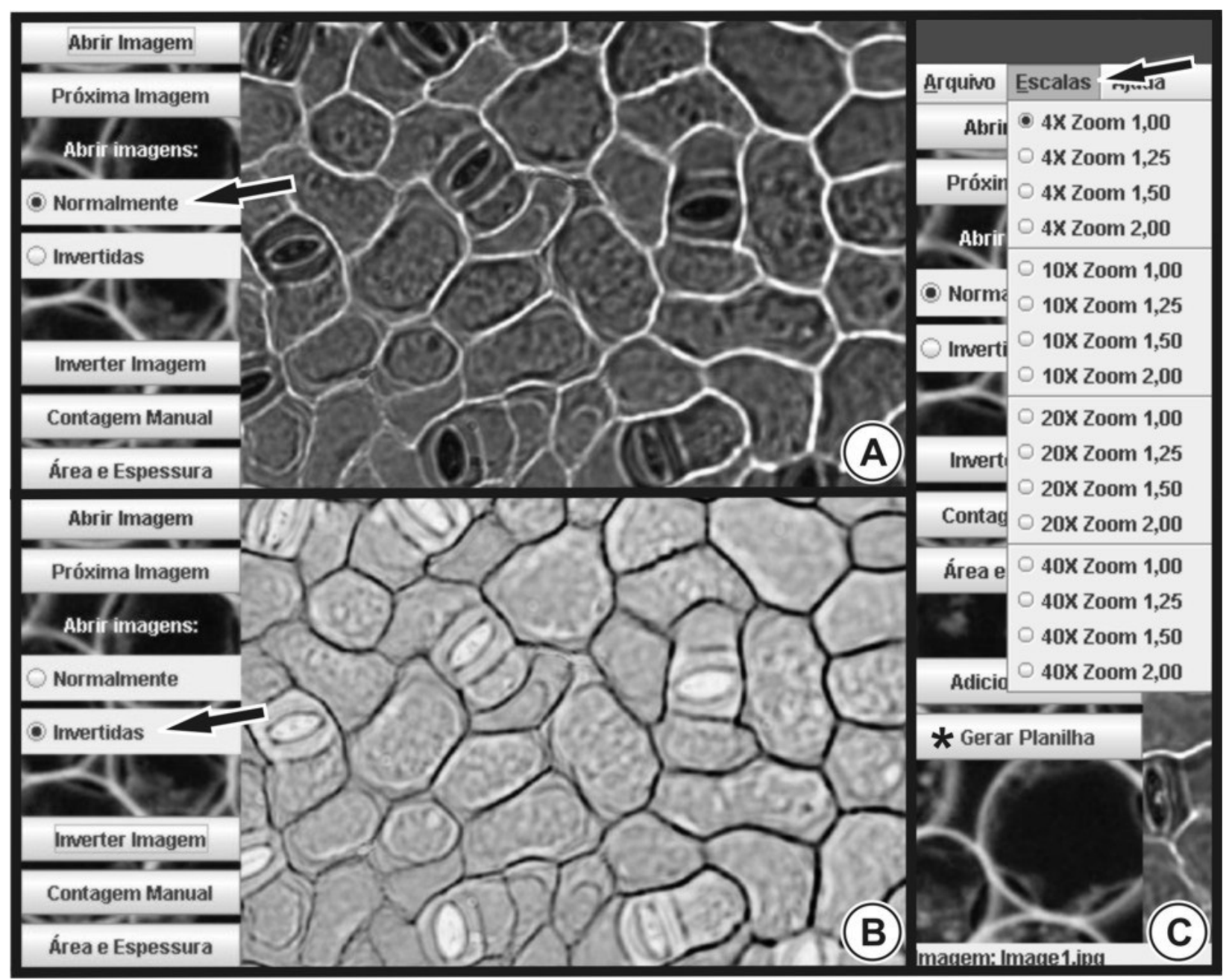

A- Comando utilizado para abrir a imagem com o contraste normal (seta). B- comando para abrir a imagem com o contraste invertido (seta). C- comandos para seleção da escala a ser trabalhada (seta) e exportação dos dados para planilha do Excel@ (*).

Figura 2 - Funções do menu lateral direito (A e B) e do menu superior (C) do ANATI QUANTI. 
se em uma vantagem do software proprietário sobre o ANATI QUANTI.

Após o término das medições em uma imagem, o usuário clica no botão "Adicionar Dados" e o software acrescenta as informações obtidas na análise, para posterior exportação dos dados para o Excel $^{\circledR}$. O botão "Gerar Planilha" cria uma planilha do $\mathrm{Excel}^{\circledR} \mathrm{com}$ os dados que foram coletados através das análises usando uma formatação adequada a uma posterior análise pelo usuário (Figura 2C), para contagem manual de estômatos e células epidérmicas propriamente ditas ou medição automática de área e espessura.

\section{Contagem manual de estômatos e células epidérmicas propriamente ditas}

A contagem de células epidérmicas propriamente ditas e estômatos é amplamente utilizada em trabalhos de Anatomia Vegetal, principalmente para cálculos de densidade e/ ou índice estomático (Paiva et al., 2003; Segatto et al., 2004; Francino et al., 2006; Tuffi Santos et al., 2006; Ferreira et al., 2007), tornando fundamental a presença desta função em softwares de análise micromorfométrica.

No ANATI QUANTI, o botão "Contagem Manual" permite ao usuário fazer o apuramento manual de células epidérmicas e estômatos. Após selecionar o comando, o software disponibiliza, no menu inferior, o recurso que está sendo utilizado. Os botões de controle situados à direita permitem distinguir os tipos celulares e cancelar uma ou todas as contagens efetuadas (Figura 3A). Com a contagem estabelecida, o software transfere os dados para um arquivo do Excel $^{\circledast}$ (nomeado pelo usuário), pré-formatado com o intuito de facilitar uma posterior análise, onde constam as seguintes informações: nome da imagem, quantidade de células epidérmicas e estômatos, cálculos de índice estomático de acordo com Cutter (1978) (Índice

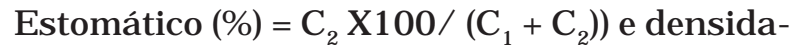
de estomática (Densidade Estomática $\left(\mathrm{mm}^{2}\right)$ $=\mathrm{C}_{2} /$ área ${ }_{\text {total }}$, em que $\mathrm{C}_{1}=$ células epidérmicas e $\mathrm{C}_{2}=$ estômatos (Figura 3B). Entretanto, caso seja desejável contar outras estruturas, como tricomas, escamas ou glândulas, basta o usuário substituir o nome do tipo celular (células epidérmicas e estômatos) na planilha do Excel $^{\circledR}$ gerada (Figura 3B). Segundo os usuários que utilizaram os dois softwares, a aquisição automática dos dados de densidade e índice estomáticos pelo ANATI QUANTI permite economia de tempo na análise das imagens e pode diminuir substancialmente a chance de erros durante os cálculos.

\section{Medição automática de área e espessura}

As medições usadas para definir a espessura ou o calibre de células, tecidos ou órgãos vegetais também são amplamente utilizadas em trabalhos com anatomia quantitativa (Paiva et al., 2003; Tuffi Santos et al., 2005; Ferreira et al., 2007). Em softwares mais gerais, o cálculo automático da espessura ou área ocupada pelo tecido não é disponibilizado de forma simples e direta, o que dificulta o acesso a usuários eventuais e/ou inexperientes, fazendo com que optem por utilizar recursos manuais, prática demorada e cansativa.

No ANATI QUANTI, após selecionar o botão "Área e Espessura", o usuário clica no fundo da imagem e o software determina a área geral e espessura média de seis retas eqüidistantes traçadas na imagem em análise (Figura 4A, B). A área apresentada pela secção transversal da folha é dada a partir da distinção entre as cores do fundo da fotomicrografia e da secção transversal da folha, sendo os dados disponibilizados em porcentagem e $\mu^{2}$. A espessura é dada pela média de seis retas verticais eqüidistantes, automaticamente traçadas quando o fundo da imagem é selecionado (Figura 4B). Em seguida, os dados são exibidos numa tabela à direita da tela. Após adicionar os dados, a planilha gerada possui as seguintes informações: nome da imagem, área foliar $\left(\mu \mathrm{m}^{2}\right)$ em secção transversal, percentual que o corte da folha está ocupando em relação à imagem como um todo e espessura média calculada $(\mu \mathrm{m})$ (Figura 4C). De acordo com os usuários do software proprietário, essa ferramenta do ANATI QUANTI diminui o tempo durante o processamento das planilhas geradas, pois exclui a necessidade de efetuar cálculos matemáticos no Excel ${ }^{\circledR}$. Adicionalmente, todos os dados são dispostos em ordem seqüencial, sem ônus de tempo de formatação, reduzindo, substancialmente, a margem de erro durante o processamento dos dados. Segundo comentários dos estudantes que utilizaram os dois 


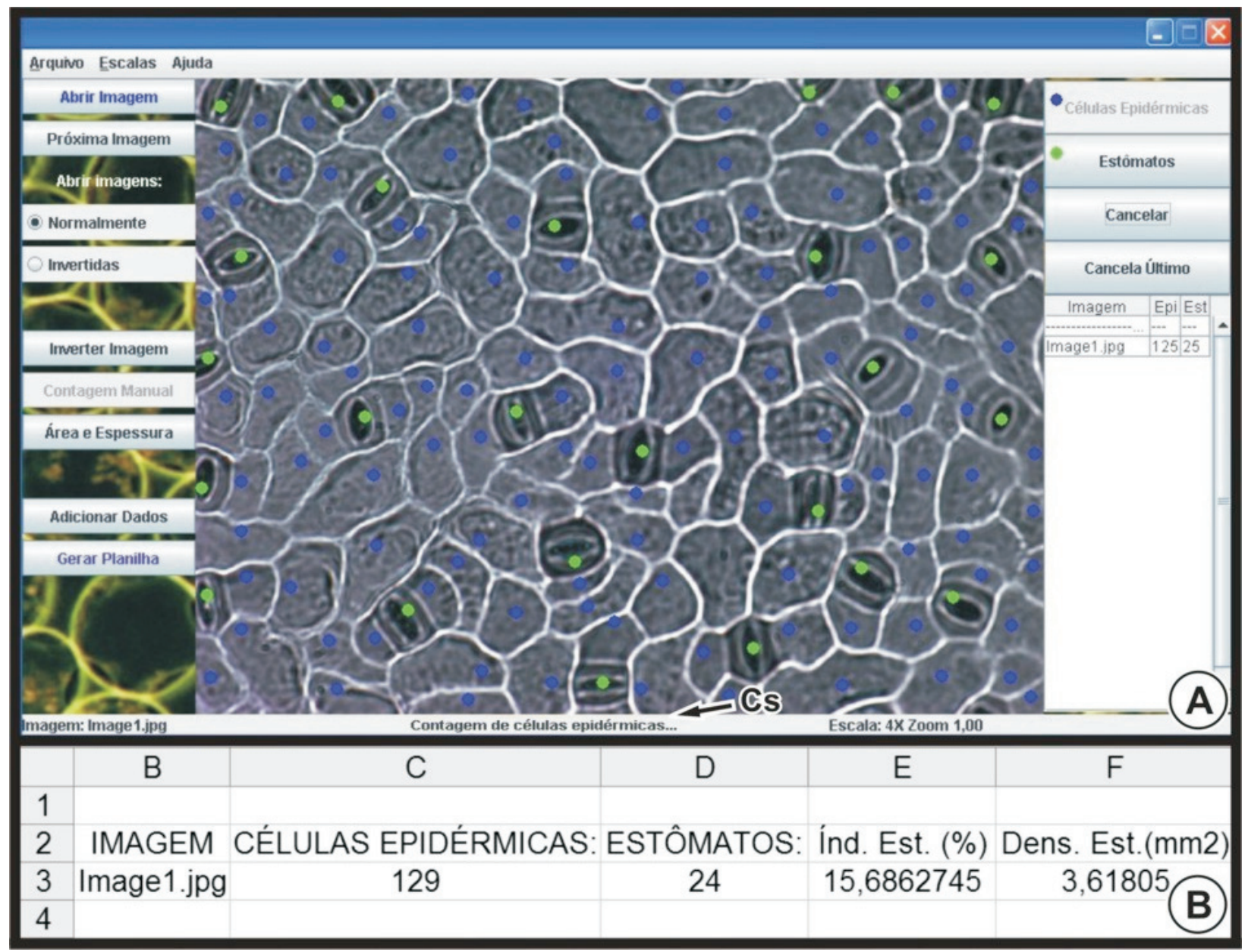

A- contagem manual de células epidérmicas (pontos azuis) e estômatos (pontos verdes). B- dados exportados da contagem manual.

Figura 3 - Contagem manual (A) e planilha do Excel $^{\circledR}$ gerada a partir do ANATI QUANTI (B).

softwares, a adição de uma ferramenta manual de medição em espessura numa futura versão do ANATI QUANTI será fundamental para trabalhos mais minuciosos.

\section{Teste de eficiência do software e pesquisa de opinião com usuários}

Os valores numéricos obtidos no ANATI QUANTI diferiram, em média, cerca de 0,5\% dos observados no software disponivel. Contudo, observou-se diferença expressiva no tempo de utilização. As imagens utilizadas no teste de eficiência foram mensuradas em 120 minutos no software proprietário e em apenas sete minutos no ANATI QUANTI. Os usuários que compararam os dois softwares também constataram maior economia de tempo no trabalho ao utilizar o ANATI QUANTI.
Dentre os pesquisadores que responderam o questionário, $67 \%$ eram estudantes de pósgraduação que utilizam o software em pesquisas ou durante atividades de disciplinas do Programa de Pós-Graduação em Botânica (UFV), $8 \%$ de docentes e $25 \%$ de graduandos.

Os entrevistados destacaram que a falta da ferramenta manual de medição de área e espessura é a principal desvantagem do ANATI QUANTI em relação ao software atualmente utilizado (Figura 5). A adição desta ferramenta para uma próxima versão, conforme comentários adicionais de alguns entrevistados, tornaria o ANATI QUANTI auto-suficiente.

Na opinião dos voluntários que participaram da pesquisa, os dois maiores atrativos do ANATI QUANTI são a inserção automática das escalas e a exportação direta dos dados para 


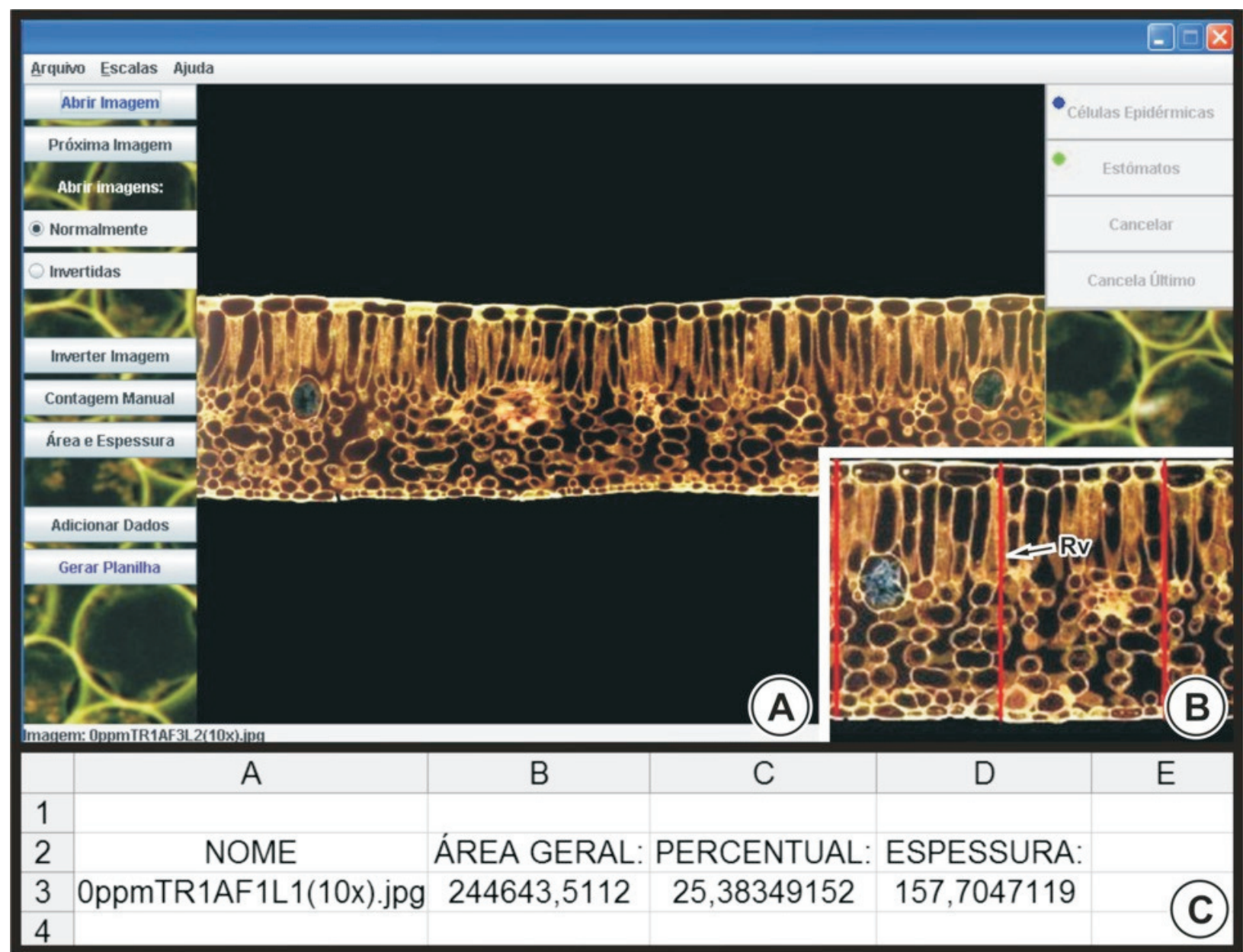

A- medidas automáticas de área e espessura. B- no cálculo de espessura, retas verticais (Rv) são traçadas e a média fornecida automaticamente. C- dados exportados.

Figura 4 - Medição automática de área e espessura (A-B) do ANATI QUANTI e planilha do Excel $^{\circledR}$ gerada.

planilhas, com todas as informações relevantes dispostas de maneira a evitar perda de tempo e eventuais erros decorrentes da formatação de dados (Figura 6).

A nova versão do ANATI QUANTI, que será disponibilizada no site da UFV (http:// www.ufv.br), já se encontra em fase final de desenvolvimento e será lançada com as ferramentas para inserção de novas escalas (provenientes de outros microscópios), medição manual de espessura e demo de utilização.

Todos os entrevistados declararam que utilizarão o ANATI QUANTI em suas pesquisas. Os resultados obtidos no teste de eficiência permitem concluir que o software fornece dados confiáveis. Atualmente, o software desenvolvido vem sendo utilizado de forma experimental em algumas pesquisas realizadas na UFV. 


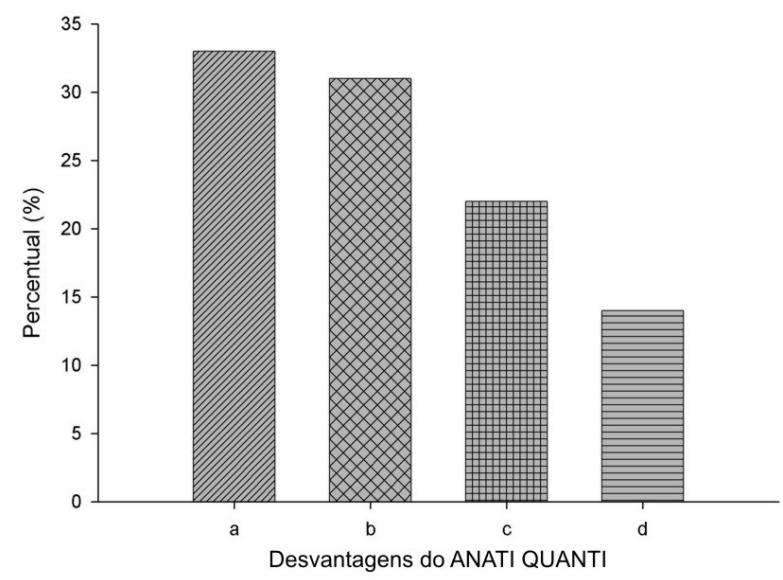

Legenda: a (falta uma ferramenta manual para medições de área e espessura), b (falta a inserção de novas escalas no ANATI QUANTI, o que permitirá utilizar o software com imagens provenientes de outros microscópios), c (falta disponibilizar na internet, para que as versões mais atuais estejam sempre disponíveis e fáceis de acessar), d (falta um demo de utilização).

Figura 5 - Porcentagem de relevância das desvantagens do ANATI QUANTI, em relação ao software proprietário, destacadas pelos voluntários da pesquisa.

\section{AGRADECIMENTOS}

Os autores agradecem a todos os graduandos, pós-graduandos e docentes da Universidade Federal de Viçosa que participaram da pesquisa.

\section{LITERATURA CITADA}

ALBUQUERQUE, M. P. Processamento de imagens: Métodos e análise. 2000. Disponível em: <http:// www.cbpf.br/ mpa/curso2.htm)>. Acesso em: out. de 2005.

ALVES DE BRITO, C. J. F. et al. Anatomia quantitativa da folha e do colmo de Brachiaria brizantha (Hochst. ex A. Rich.) Stapf e B. humidicola (Rendle) Schweick. R. Bras. Zootec., v. 33, p. 519-528, 2004.

BARROS, A. L. Morfo-anatomia e teor de nutrientes em três espécies vegetais cultivadas em sistema "wetland construído". 2005. 70 f. Dissertação (Mestrado em Botânica) - Universidade Federal de Viçosa, Viçosa, MG, 2005.

BURROWS, G. E.; BOAG, T. S.; STEWART, W. P. Changes in leaf, stem, and root anatomy of Chrysanthemum cv. Lillian Hoek following paclobutrazol application. J. Plant Growth Regul., v. 11, p. 189-194, 1992.

Planta Daninha, Viçosa-MG, v. 25, n. 4, p. 649-659, 2007

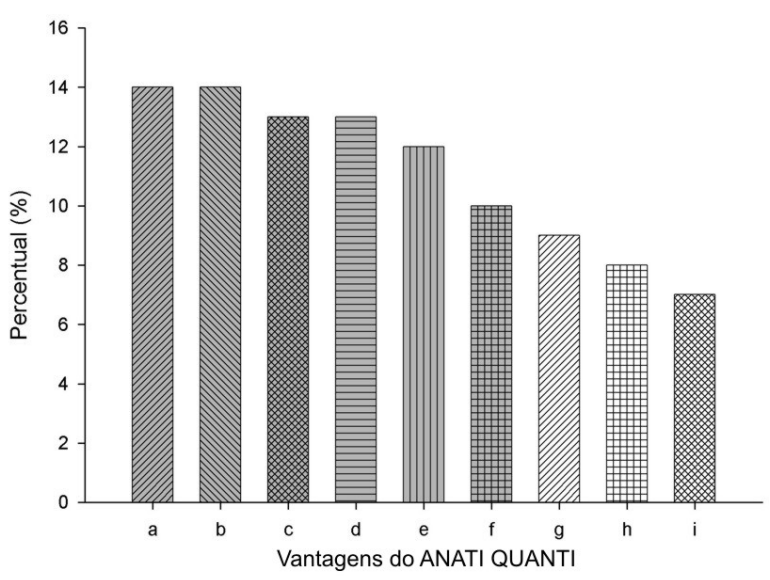

Legenda: a (a exportação dos dados é direta, é nas planilhas geradas, todas as medições já aparecem com o nome da figura ao lado, o que reduz a perda de tempo formatando as planilhas do Excel $\left.{ }^{\circledR}\right)$. b (as escalas já estão inseridas, não sendo necessário calibrar o software). c (o software é simples e específico para o que quero utilizar, com poucos botões e funções, o que facilita a memorização e utilização das suas funções). d (a contagem de células é prática, havendo opções de botões diferenciados para estômatos e células epidérmicas propriamente ditas; dessa forma, os dados são exportados separadamente para o Excel $^{\circledR}$, além de não haver necessidade de calcular densidade e índice estomático). e (o software é gratuito, o que evita a pirataria de softwares pagos e facilita o acesso). f (a abertura das imagens é fácil, basta selecionar a pasta que as imagens vão abrindo em ordem seqüencial). g (o software é em português, auxiliando na compreensão das suas funções). h (a imagem pode ser aberta com contraste invertido, o que reduz o tempo de trabalho na edição das imagens em outros softwares). i (funciona na plataforma Linux e Windows).

Figura 6 - Porcentagem de relevância das vantagens do ANATI QUANTI, em relação ao software proprietário, destacadas pelos voluntários da pesquisa.

CUTTER, E. G. Plant anatomy: cells and tissues. Part I. London: William Clowes and Sons, 1978. 315 p.

DICKISON, W. C. Integrative plant anatomy. San Diego: Academic Press, 2000. 533 p.

FACON, J. Processamento e análise de imagens. Curitiba: Pontifícia Universidade Católica do Paraná, 2005. $128 \mathrm{p}$.

FALCÃO, A. X. Fundamentos de processamento de imagem digital. Disponível em: <http:// www.dcc.unicamp.br/ cpg/materialdidatico/mo815/9802/ curso/node14.html>. Acesso em: março de 2006. 
FEDER, N.; O'BRIEN, T. P. Plant microtechnique: some principles and new methods. Am. J. Bot., v. 55, p. 123-142, 1968.

FERREIRA, E. A. et al. Estudos anatômicos de folhas de espécies de plantas daninhas de grande ocorrência no Brasil. IV - Amaranthus deflexus, Amaranthus spinosus, Alternanthera tenella e Euphorbia heterophylla. Planta Daninha, v. 21, n. 2, p. 263-271, 2003.

FERREIRA, E. A. et al. Anatomia quantitativa da lâmina foliar de genótipos de cana-de-açúcar. Planta Daninha, v. 24, n. 1, p. 25-34, 2007.

FILHO, L. E. Extração semi-automática de feições lineares e a calibração dos parâmetros intrínsecos de câmeras. 2007. Disponível em: <http://www.lps.usp.br/ $\sim$ hae/psi5796-05/seminarios/LeonardoErcolin-artigo.pdf $>$. Acesso em: junho de 2007.

FRANCINO, D. M. T. et al. Anatomia foliar e caulinar de Chamaecrista trichopoda (Caesalpinioideae) e histoquímica do nectário extrafloral. Planta Daninha, v. 24, n. 4, p. 695705, 2006.

GONZALEZ, R. C.; WOODS, R. E. Digital image processing. New Jersey: Prentice Hall, 2002. 793 p.

LEITÃO, C. A. E. et al. Anatomy of the floral, bract, and foliar nectarines of Triumfetta semitriloba (Tiliaceae). Can. J. Bot., v. 83, p. 279-286, 2005.

MARANHO, L.T. et al. Efeitos da poluição por petróleo na estrutura da folha de Podocarpus lambertii Klotzsch ex Endl., Podocarpaceae. Acta Bot. Bras., v. 20, p. 501-750, 2006.

PAIVA, E. A. S. et al. The influence of light intensity on anatomical structure and pigment contents of Tradescantia pallida (Rose) Hunt. cv. purpurea Boom (Commelinaceae) leaves. Braz. Arch. Biol. Technol., v. 46, p. 617-124, 2003.
SANT'ANNA-SANTOS, B. F. et al. Utilização de parâmetros morfoanatômicos na análise da fitotoxidez do flúor em folhas de Magnolia ovata (A. St.-Hil.) Spreng. (Magnoliaceae). R. Árvore, v. 31, p. 761-771, 2007.

SEARA, D. M. Algoritmos para detecção de bordas. 2007. Disponível em: <http://www.inf.ufsc.br/ visao/1998/seara/ index.html>. Acesso em: junho de 2007.

SEGATTO, F. B. et al. Técnica para o estudo da epiderme foliar de batata. Ci. Rural, v. 34, p. 1597-1601, 2004.

SOUKUPOVA, J.; ROCK, B.N.; ALBRECHTOVA, J. Comparative study of two spruce species in a polluted mountainous region. New Phytol., v. 150, p. 133-145, 2001.

TUFFI SANTOS, L. D. et al. Efeito do glyphosate sobre a morfoanatomia das folhas e do caule de Commelina diffusa e C. benghalensis. Planta Daninha, v. 22, p. 101-107, 2004.

TUFFI SANTOS, L. D. et al. Crescimento e morfoanatomia foliar de eucalipto sob efeito de deriva do glyphosate. Planta Daninha, v. 23, n. 1, p. 133-142, 2005.

TUFFI SANTOS, L. D. et al. Características da epiderme foliar de eucalipto e seu envolvimento com a tolerância ao glyphosate. Planta Daninha, v. 24, n. 3, p. 513-520, 2006.

VEROPOULOS, K. et al. The automated identification of tubercle bacilli using image processing and neural computing techniques. In: INTERNATIONAL CONFERENCE ON ARTIFICIAL NEURAL NETWORKS, 8., 1998, Sweden. Proceedings... Sweden, 1998. v. 2. p. 797-802.

WIKIPÉDIA. Wikipédia, a enciclopédia livre. Disponível em: <http://pt.wikipedia.org/wiki/ Software_propriet\%C3\%A1rio>. Acesso em: junho de 2007. 